\title{
Remote Sensing Applied to Regional-Scale Mapping of Solar Potential-Case Study on Florianopolis Island
}

\author{
Vivian da Silva Celestino Reginato \\ Department of Civil Engineering, Federal University of Santa Catarina (UFSC), Florianópolis, Brazil \\ Email: viviancart@yahoo.com.br
}

How to cite this paper: Reginato, V. da S.C. (2020) Remote Sensing Applied to Regional-Scale Mapping of Solar Potential-Case Study on Florianopolis Island. Journal of Geographic Information System, $12,432-450$.

https://doi.org/10.4236/jgis.2020.125026

Received: August 9, 2020

Accepted: September 13, 2020

Published: September 16, 2020

Copyright $\odot 2020$ by author(s) and Scientific Research Publishing Inc. This work is licensed under the Creative Commons Attribution International License (CC BY 4.0).

http://creativecommons.org/licenses/by/4.0/

\begin{abstract}
Satellite imagery is used for many activities in different areas of the planet, including searching for alternative and sustainable sources to meet growing energy demand to reduce greenhouse gas (GHG) emissions. One way to minimize these effects and expand energy parks is to encourage local generation through the use of renewable sources, such as solar energy, which is free and affordable in many regions of the planet, but that in Brazil is not yet a reality. In order to make an assertive decision when installing a solar power system, one needs to use tools that involve remote sensing and geographic information systems (GIS), and compile information and variables that are relevant to the subject of solar power generation and take into account the inherent geographic space. In this context, the main objective of this work is to develop a GIS model to identify areas with solar potential on a regional scale using active remote sensor images and previously available solar models. To validate the model, this study used an area on the island part of the city of Florianópolis in Santa Catarina State-Brazil, which suffers from repeated climatic events which cause long power cuts, as its distribution occurs by air all over the island. Through the "solar analist" function of ArcGIS and the matrix bases derived from the Digital Model of the Space Shuttle Topography Mission (SRTM) with $30 \mathrm{~m}$ of spatial resolution and the supervised classification of panthromatic and multispectral images fused from LandSat 8 satellite, were generates indicative maps of the areas with solar potential. The results pointed to a high solar potential in the all year and that could be better explored by public managers and also by individual consumers.
\end{abstract}

\section{Keywords}

Solar Energy, Remote Sensing, SRTM, Geographic Information Systems (GIS) 


\section{Introduction}

In 1957, a terrestrial object, built by the hand of man, was launched into the universe, where it revolved around the earth for a few weeks according to the same laws of gravitation that governs the movement of celestial bodies-the sun, moon and stars. It is true that the artificial satellite was neither the moon nor a star; it was not a celestial body that could proceed in its circular orbit for a period of time that, for us, mortals limited to Earth's time, would last forever [1].

Hannah Arendt was referring to Sputnik, the world's first orbiting artificial satellite, which paved the way for new technology called Remote Sensing, which is the art and science of collecting information about an object without being in direct physical contact with it. It uses electromagnetic energy emitted or reflected by the targets as a physical principle for capture. The oldest system used for this capture is the photographic camera, an invention made in the nineteenth century [2]. After photography, aerial platforms emerged (balloons, kites, rockets, aircraft, among others).

According to [1], the situation created by sciences has great political significance, so much so that photographic recognition of the earth originated during the 1st and 2nd world wars and remains to this day. According to [2], the arms race between the United States (US) and the Soviet Union (USSR) that took place during the Cold War emphasized the development of intelligence gathering technologies to spy on the enemy's arsenal. This race revolutionized the concept of war. According to [3], it resulted in an asymmetry in postmodern combat, and Americans have since demonstrated the vast superiority of their weapons and satellites, whose greatest exponent is the Global Positioning System (GPS) constellation, operating since the 1990s.

Free remote sensing images have been used for the purposes of peace, science, education and technology in many countries. Examples of these images include those from active sensors from the Space Shuttle Topography Mission (SRTM) and those from passive sensors such as the ones from the Landsat series. Such images are fundamental tools/resources for analysts to identify problems, visualize panoramas and propose viable policy alternatives for decision making in territorial management.

Robert Cowell, an American Forest Engineer, realizing the potential of satellite imagery, developed, during the 1960s, the multi-concept as a useful and accurate scientific method of image interpretation through the development of four types of analysis: multispectral, multidisciplinary, multiscale and multitemporal. Ever since, image analyses have involved the use of various scenes, scales, teams, times and qualities, but all are performed taking into account the changes in space and/or time. They also allow predictions to be made, and understanding the impact of anthropic intervention is paramount.

In the contemporary era, in which the population increases and uses energy more and more, it is urgent and contingent to progress without losing sight of the preservation of natural resources. Finding alternatives that use renewable 
sources of energy are not only necessary but also vital for the preservation of living beings, because the environmental damage caused by greenhouse gas emissions is irreversible, with an increase in the ozone hole, global warming, melting of ice caps and climate change, just to mention a few notable examples.

Several sources of energy can be used as alternatives to the use of polluting energies. These energies, considered to be renewable-or soft, as some authors prefer, e.g., [4] - are "those originated in nature, such as solar, wind, ocean or geothermal energy, used locally and in hybrid form to avoid energy costs and transport expenses".

To allow the visualization of future scenarios in physical spaces and to collaborate in the current decision-making process in the identification of renewable energy potential, Geographic Information Systems (GIS) have been used as tools at various scales, levels of abstraction and spatialization of phenomena. Abstract phenomena, such as temperature and solar radiation, are some examples.

The solarimetric atlases produced and the solar radiation models that are already developed and commercially available are examples of applications that were produced using GIS. However, both atlases (because they have a small scale) and radiation models (because they are more precise in point-based identification) do not meet the need for investigation of solar potential to be applied at regional scales (models that can be applied to municipalities, for example). A new generation of spatial models that combine the respective advantages of point-specific solar radiation models with small scale atlas visualization is required to make regional-scale insolation/radiation models quick and accurate.

But in order to make an assertive decision regarding the definition of areas with potential to generate energy from solar sources at a regional scale, one has to check for the fundamental premises for this potential to exist, e.g., relief and proper aspect. The most appropriate techniques to perform these analyses still include the use of products such as remote sensing images and/or photogrammetry as well as GIS tools; firstly, to generate digital models and, secondly, to perform spatial analysis of them. Such analysis is necessary so that the information coming from the terrestrial surface and the environment, when geographically spatialized, can become knowledge that allows assertive decision making.

In this context, the main objective of this work is to develop a GIS model to identify areas with solar potential on a regional scale, using active remote sensor images and previously available solar models, using as study area the Florianópolis Island.

It is worth mentioning that, in Brazil, the production of energy by solar source is incipient and in the study area used, its use is negligible, close to other places in the world, such as Portugal and Spain, for example. The production of energy, mainly in the country, occurs by water, and it is transported over great distances via transmission lines. The exploitation of solar energy, both thermal and photovoltaic, could take place in a more organized and subsidized way, including by public management, if there was an economic and political interest, as the Island (study area) is a place that suffers numerous weather events and it lacks electric- 
ity when this occurs because the transmission and distribution of energy are all carried out via overhead cables. Individualized solar production (which can be connected to the grid), in this case, would be an intelligent way to reduce the losses caused by such events, in addition to guaranteeing energy in times of drought due to water stress due to the absence of rain in the generation units hydropower (hydroelectric). It is said that the last climatic event that hit Florianópolis occurred at the end of June 2020 and the entire island was without electricity, and that absence lasted between a few hours in some neighborhoods (less impacted) and several days in others (most impacted). Some places have been without power for more than seven days in a row, including home and commercial establishments. The use of solar energy, in this aspect, would collaborate for a faster recovery of the places affected by the events, besides allowing an increase in the quality of life of the population and also moving the economy.

\section{Renewable or Soft Energies}

Renewable or soft energies are those that use the forces of nature to generate energy without harming the environment and without large logistic systems to carry the energy generated. The author [4] points out that the process of energy generation, until final consumption, must follow a sustainable and therefore smooth path:

The "soft energy path" assumes that energy is but a means to social ends, and is not an end in itself. Soft energy paths involve efficient use of energy, diversity of energy production methods (matched in scale and quality to end uses), and special reliance on co-generation and "soft energy technologies" such as solar energy, wind energy, biofuels, geothermal energy, wave power, tidal power, etc. [4].

According to [5], solar energy is an inexhaustible, free and non-polluting source, since the sun reaches the earth in thermal and luminous forms, but the capture of such radiation varies according to location, as it depends on latitude, season and various atmospheric conditions such as cloudiness and relative humidity.

A photovoltaic system, for example, does not need sunlight to operate; it can also generate electricity on cloudy days. This is because the surplus energy available on the grid serves as credit that can be used by the consumer when solar energy is not available.

The growth rate of installed photovoltaic energy in recent years has exceeded all forecasts, thus showing the potential of this technology as a source of energy worldwide. Importantly, most of the installed capacity corresponds to grid-connected installations, accounting for $98 \%$ of global capacity, although there is recent interest in stand-alone installations and small-scale systems, especially in remote, hard-to-reach areas. According to the Renewable Energy Policy Network for the 21st Century (REN21), grid-connected photovoltaic systems were the world's fastest growing generation technology in 2006 and 2007 [6].

Because Brazil is a country located mostly in the intertropical region, it has 
great potential for harnessing solar energy throughout the year [7] and [8] using the thermal and photovoltaic systems. Because of climatic characteristics, the former is more suitable to be explored in the South and Southeast regions of the country, while the latter, in the North and Northeast regions, in communities isolated from the electric power grid.

This potential was found by the National Institute for Space Research (INPE) when the Brazilian Solar Energy Atlas was published in 2006, through the National Organization System of Environmental Data (SONDA), The Solar and Wind Energy Resource Assessment (SWERA), funds from the United Nations Environment Program (UNEP) as well as funds from the Global Environment Fund.

Through geoprocessing techniques, data on Global Horizontal Solar Irradiation-annual average for 2006-from the Brazilian Solar Energy Atlas, can be accessed by interested parties. However, as it is a product of a very large spatial scope, it has limitations regarding scale and accuracy, and it is not recommended for identifying solar potential regionally or locally.

According to [9], incident solar radiation can be measured by terrestrial weather stations and meteorological satellites, and/or estimated using models. There are several solar models available in the literature, which vary in detail about the input parameters and hence the output map. The two most commonly used examples of solar radiation models are ArcGIS' Solar Analyst [10] and the Photovoltaic Geographic Information System (PVGIS) [11].

\section{The State of the Art of Gis in Renewable Energy and Spatial Insolation Models}

For associating qualitative and quantitative phenomena arising from the earth's surface, whether of discrete, continuous or abstract characteristics, and transforming them into knowledge that can be analyzed and allow decision-making in territorial management, the most used tool nowadays involves GIS, since the solutions presented guarantee a quality result, the possibility of quality measurement and evaluation, as well as considerable cost and time reductions. GIS is a set/system of hardware, software and procedures designed to support the collection, management, analysis, modeling and visualization of georeferenced data to solve planning and management problems [12].

Geographic modeling is one of the main steps of GIS, and it has gained relevance in recent years as a result of methodological and technological developments. On the one hand, geography, cartography and other earth-related sciences have developed analytical tools and, on the other hand, hardware and software components also evolved substantially and enable spatial analysis. At the same time, the existence of several data production and availability projects has complemented the offer and provided support for implementation and testing of various models.

Spatial insolation models are also geographic models and can be categorized 
into two types: point-specific and area-based. Point-specific models calculate insolation for a location based upon the geometry of surface orientation and visible sky. The local effect of topography is explained by empirical relationships, visual estimation or, more precisely, by the aid of upward-looking hemispherical viewsheds [13].

Point-specific models can be highly accurate for a particular location, but it is not feasible to build a site-specific model in a region. In contrast, area-based models calculate insolation for a geographic area, and they calculate surface orientation and shadow effects from a DEM. These templates provide important tools for understanding the processes of a region.

The SolarFlux model [14] [15] and [16], developed for use on the ARC/INFO GIS platform (Environmental Systems Research Institute, ESRI), simulates the influence of shadow patterns on direct insolation using the Hillshade function at discrete intervals over time.

The Solar Analyst model builds on the strengths of point-based and area-based models. In particular, it generates an upward-looking hemispherical viewshed, essentially producing the equivalent of a hemispheric (fisheye) photograph [17] and [18] for each location in a DEM. Hemispherical viewsheds are used to calculate insolation for each location and produce an accurate insolation map. It calculates the integrated insolation for any time period using latitude and elevation of the site, surface orientation (aspect), shadows cast by the surrounding topography, daily and seasonal changes in solar angle and atmospheric attenuation. It is implemented as an extension of ArcGIS.

According to the website https://ec.europa.eu/jrc/en/pvgis [19], PVGIS provides free and open Internet access to solar radiation and temperature data for photovoltaic potential performance evaluation. Its features are: photovoltaic potential; solar radiation and temperature; complete time series of hourly values of solar radiation and photovoltaic performance; typical weather year data for nine climate variables; ready-to-print maps (by country or region) of solar resources and photovoltaic potential. It contains different solar radiation databases (based on satellite data and reanalysis products), covering the entire terrestrial territory. It also offers print-ready maps solar and photovoltaic potential, in PDF and PNG formats for individual regions and countries.

Several studies have been conducted to include geographic modeling in multipurpose planning and decision-making activities, not just those involving database structures. In order to clarify decision processes involving various projects and problems that require a spatial solution, the adaptation of GIS models has been a reality in the search for alternatives in power generation.

\section{Definition and Characterization of the Study Area}

The study area (see Figure 1) covers the largest island of the city of Florianópolis, with $421.23 \mathrm{~km}^{2}$. It is located on the Atlantic Ocean, in the center of the coast of the Santa Catarina-Brazil, in latitude $27^{\circ}$ South and longitude $48^{\circ}$ West. 


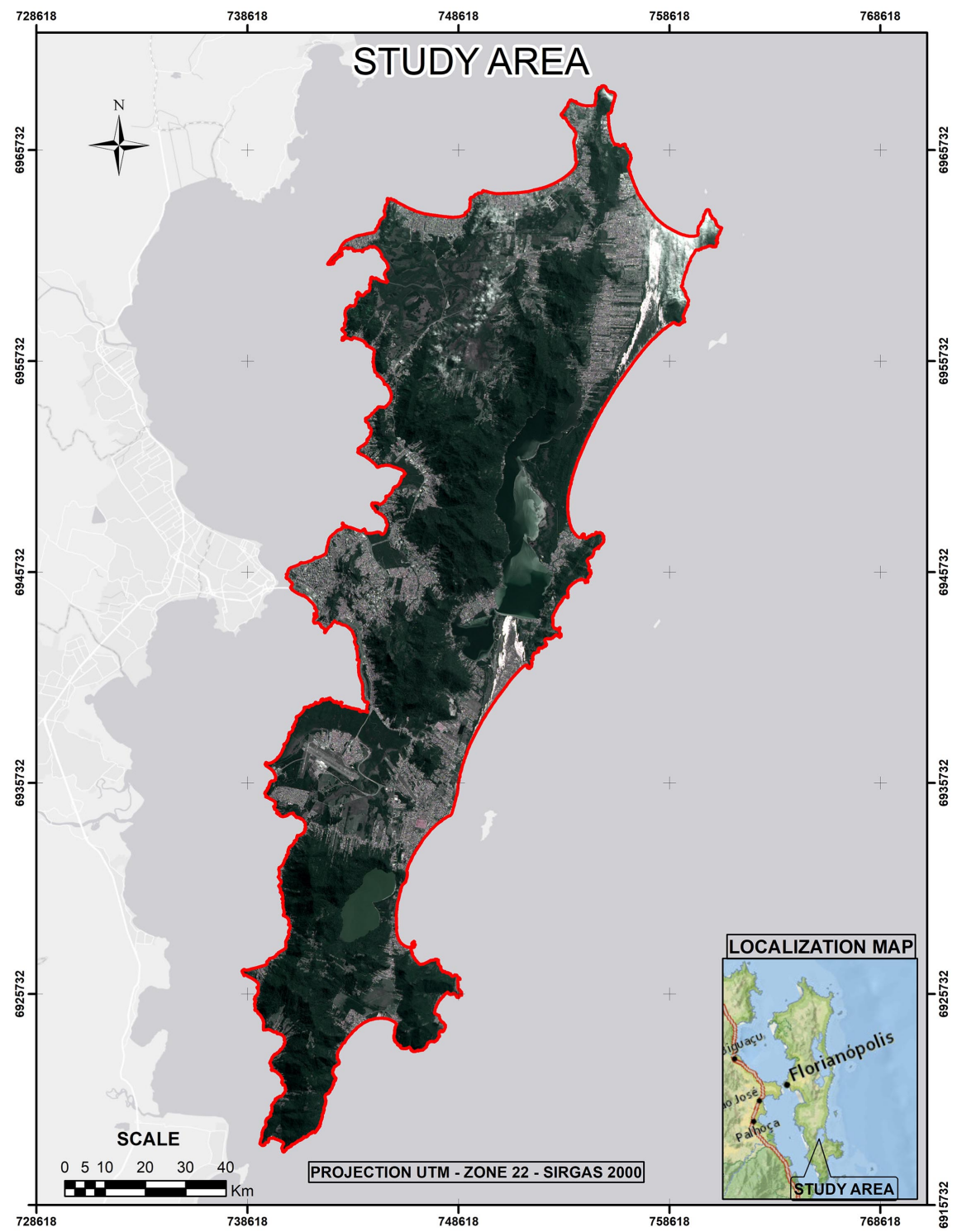

Figure 1. Study area.

Florianópolis Island has an elongated and narrow shape, with an average length of $55 \mathrm{~km}$ and an average width of $18 \mathrm{~km}$. With a very jagged coastline, it has several coves, tips, islets, bays and lagoons. It is situated parallel to the continent, separated by a narrow channel. Its relief is formed by mountainous and discontinuous ridges which serve as a watershed. The highest point is the Ribeirão hill, with $532 \mathrm{~m}$ of altitude. Parallel to the mountains, sparse plains emerge eastward and in the northwestern portion. On the east side of the island, there is presence of dunes formed by the action of the wind.

There is no consensus on the number of beaches on Florianópolis Island; it can range between 42 and 100 beaches, all of which are very different in terms of access, amount of beach (sand), infrastructure, beauty, water temperature, wave formation and etc.

The climate, according to the Köeppen classification [20], which analyzes both 
temperature and precipitation simultaneously, is considered to be humid mesothermal, with hot summers, cold winters and humidity all year round. According to Strahler's climate classification [21], which is based on climate controls and rainfall characteristics, the climate is considered to be Subtropical Humid, controlled by tropical air masses and polar air masses, with abundant rainfall, all year round, with maximum rates occurring in the summer, mostly in January.

With regard to winds, according to data from the Integrated Center for Meteorology and Water Resources of Santa Catarina (CLIMERH), in the last 80 years, there has been a predominance of north winds (36.9\%), followed by southeast winds (16.9\%), south winds (15.7\%), northeast winds (10.0\%), northwest winds (2.8\%) and southwest winds (1.1\%). The prevailing winds in Florianópolis blow from the north quadrant, with average velocity of $3.5 \mathrm{~m} / \mathrm{s}$, but the fastest winds blow from the south with average velocities of $10 \mathrm{~m} / \mathrm{s}$. The south winds precede the entry of cold fronts and present gusts that reach up to $22 \mathrm{~m} / \mathrm{s}$ [22].

The average temperature recorded by the Florianópolis Main and Synoptic Climatological Station during the period from 1911 to 2009 was $20.6^{\circ} \mathrm{C}$. The quarter with the highest average temperatures was January, February and March, with $24.5^{\circ} \mathrm{C}$, and the lowest average temperatures were recorded in the months of June, July and August: $17.6^{\circ} \mathrm{C}$. There is a great variety of vegetation because it is located in a coastal zone.

Originally, " $90 \%$ of area of the territory of the island was covered by vegetation; 74\% of this vegetation was the Atlantic Forest, 9\%, mangroves; 7\%, beach$e s$, dunes and sandbanks, and the rest was occupied by dunes without vegetation (4\%) and by lagoons (6\%)". However, especially as a result of continuous housing development activity in several areas, the vegetation has been devastated in several areas [23].

The island has a unique biogeography with several ecosystems: mangroves, sandbanks, lagoons, dunes, beaches, rocky shores, forests. Each one of them has a vital role in the ecological balance and the maintenance of quality of life, hence many of them are legally established as Conservation Units (CUs). There are 13 CUs on the Island: 7 parks, 1 extractive reserve, 1 private natural heritage reserve, 1 environmental protection area, 2 environmental monuments and 1 ecological station. Importantly, in these areas, construction is not allowed, hence structures to capture energy via renewable sources cannot be installed.

The economy in Florianópolis is centered around the public, commerce and services sectors, with a main focus on tourism. Industry and agriculture are not exploited for environmental reasons. However, the capital is prominent in the technology industry with approximately 300 companies. Artisanal fishing, an integral part of the culture of the island, which once provided subsistence to many native families, declined in the 1990s with the advance of industrial fishing. On the other hand, there has been a growth, in the last two decades, of shellfish and oyster cultivation, which makes Florianópolis the largest oyster producer in Brazil. 
Regarding the generation and consumption of energy by renewable sources, there is not enough data to perform a quantitative analysis of the real situation of Florianópolis Island. It is known that viability of wind power generation, a priori, requires conditions that are not found in most Brazilian municipalities, including Florianópolis, which has large areas of vegetation, hills and also extreme weather events such as extratropical cyclones that prevent the construction of wind farms, for example. The potential for insertion of stand-alone plants in households should be investigated, but there are not enough data from meteorological stations at different wind measurement heights to enable the identification of this possible wind potential in Florianópolis. The only data on average wind speed points to an inconstant value of only $3.5 \mathrm{~m} / \mathrm{s}$; according to [22], this is not considered to be sufficient to ensure the minimum potential of 3.6 $\mathrm{m} / \mathrm{s}$, as indicated by [5].

The energy generated by water sources, even in small format, needs appropriate relief and large areas of land for flooding (to obtain sufficient water drop height to generate potential energy). It is therefore not suitable for exploration in cities or areas of environmental preservation; hence it is not present on Florianópolis Island.

Some factors influence the retention of solar energy under the surface, such as geographical (relief and appearance) and climatic (atmospheric dynamics, maritimity and continentality) ones. The municipalities with the highest surface solar retention are far from the coast. But the analysis of the data provided by the Solar Atlas for the Florianópolis island shows the existence of absolute global solar radiation between $4500 \mathrm{wh} / \mathrm{m}^{2}$ and $4700 \mathrm{wh} / \mathrm{m}^{2}$ (watt hour per square meter) [24].

Photovoltaic solar energy is explored in households and in some companies, such as Eletrosul, as well as in research projects (e.g. UFSC Fotovoltaica). Solar thermal energy is also explored in households.

\section{Materials and Methods}

To develop the proposed method, first a bibliographic research was conducted in different bibliographic sources; then, an energy matrix (by renewable source) was chosen, taking into account the needs of Florianópolis Island. It was found that solar power was the most suitable source of energy to be surveyed, because of its availability, privileged geographical location, no need for transportation/logistics for use, and scarce use.

The second step was to identify which conventional and primary cartographic information and products would be considered as essential to generate secondary information in order to identify solar energy potential, as well as to check their free, online availability. ESRI's ArcGIS was defined as the GIS software to develop the model.

The use of a DEM was considered to be essential for collecting information on altitude, inclination, slope to generate the solar potential by aspect of the 
mapped surface. The DEM used a mosaic of $30 \mathrm{~m}$ pixel SRTM images as input to generate solar potential per aspect.

To estimate the solar potential by aspect, weights were defined for the different solar paths applied to the study region (considering the geographical location of Florianópolis Island) through Analytic Hierarchy Process (AHP). Flat relief regions (upward or flat aspect) have excellent potential for solar uptake, so they were assigned weight 5 . The north-facing surfaces have very high potential, and were assigned weight 4 . The surfaces facing northeast and northwest have high potential, and were assigned weight 3 . The surfaces facing east and west have medium potential, and were assigned weight 2 . The surfaces facing southeast and southwest were assigned weight 1 because they have low potential, and the surfaces facing south were assigned weight 0 because they have null potential (do not receive insolation throughout the year). Figure 2 and Table 1 show details of this definition in the wind rose.

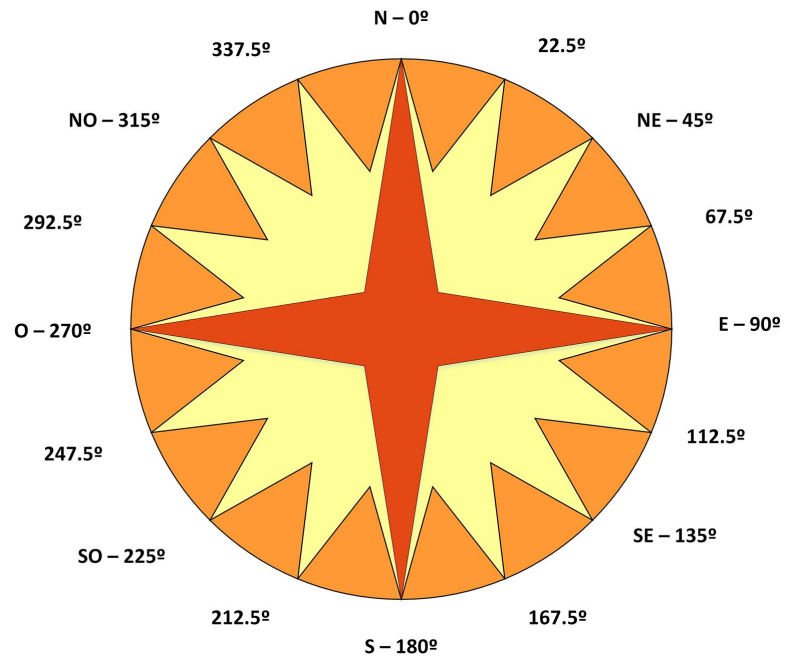

Figure 2. Wind rose.

Table 1. Weights by potential and aspect (solar orientations) of the study area.

\begin{tabular}{cccc}
\hline Aspect/Solar orientations & Potential & Solar Orientation & Weight \\
\hline Flat & Excellent & $-1^{\circ}$ & 5 \\
North & Very High & $337.5^{\circ}$ to $360^{\circ}$ and $0^{\circ}$ to $22.5^{\circ}$ & 4 \\
Northeast & High & $22.5^{\circ}$ to $67.5^{\circ}$ & 3 \\
Northwest & High & $292.5^{\circ}$ to $337.5^{\circ}$ & 3 \\
West & Medium & $247.5^{\circ}$ to $292.5^{\circ}$ & 2 \\
East & Medium & $67.5^{\circ}$ to $112.5^{\circ}$ & 2 \\
Southeast & Low & $112.5^{\circ}$ to $167.5^{\circ}$ & 1 \\
Southwest & Low & $212.5^{\circ}$ to $247.5^{\circ}$ & 1 \\
South & Null & $167.5^{\circ}$ to $212.5^{\circ}$ & 0 \\
\hline
\end{tabular}


There was also a need to collect information on land use and occupation, which could come from either supervised satellite image classifications or from aerial photogrammetric restitution or from thematic cartographic bases to define the restrictions that should be taken into account in mapping solar energy potential, such as CUs, for example. Based on this definition, a mosaic of LandSat 8 (United States Geological Survey, USGS) images with $30 \mathrm{~m}$ pixel was used. They were fused from the red, green and panchromatic bands with a final resolution of $15 \mathrm{~m}$ and after that, supervised classification was performed to extract 6 classes of land use and occupation (tree, shrub, urban, exposed soil, dunes and field). The class of tree vegetation was considered as the most important to define the restrictions because it can be correlated with the native forest of the region. The 13 CUs identified in Florianópolis, previously mentioned in item 3, were considered as restricted areas. Thus, these areas, after rasterization to a 15 $\mathrm{m}$ pixel, formed another restriction class called CU.

The ModelBuider tool was selected to build the GIS model and the Area Solar Radiation function was chosen to calculate the global radiation of the study area. They are both from ArcGIS. The Area Solar Radiation function also uses a DEM as input. For this purpose, the same $30 \mathrm{~m}$ resolution SRTM image mosaic was used to generate the potential by aspect. The following input parameters were entered: the year 2019; $14 \mathrm{~h}$ of daily radiation; 30-minute frequency; average geographical latitude of $27.5^{\circ} \mathrm{S}$; sky size resolution of 200; diffusion factor 0.3; transmissivity of 0.5 e; uniform sky diffusion model. The calculated global radiation returns the total value accumulated in the year; therefore, a calculation was performed to obtain the average daily radiation value in $\mathrm{KW} \cdot \mathrm{h} / \mathrm{m}^{2}$ using the raster calculator. Absolute global mean daily values (absolute radiation) were determined.

For a better representation of the solar potential reality of the study area, the solar potential by aspect was multiplied by the absolute average daily values (absolute radiation), which generated the relative solar potential values. For investigation of the final solar potential, the restriction relative to tree vegetation (strongly correlated with the occurrence of Permanent Protection Area (PPA)) and also the CU class-was also multiplied as null value (weight 0 ). No other restrictions were considered because, a priori, solar panels can be installed in urban environments (roofs) as well as in water reservoirs. In the end, it was possible to identify the areas with potential to generate energy from the solar source for the Florianópolis Island region. Figure 3 shows a flow chart of the materials and methods used in this study.

\section{Results and Discussions}

The development of the model and its application allowed to present results in two distinct planes: the application in Modelbuilder where the flow was produced for identification of areas with solar potential (Figure 4), and the production of maps identifying the areas with potential to generate energy from the solar renewable source. Figure 4 can be seen that in blue are the cartographic bases 
used (shapes or rasters), in yellow are the functions or operations used to perform transformations in the model and in green are the products generated, that is, the results of the integrations or algebras carried out.

Table 2 and Figure 5 show the amount of solar potential by geographical aspect of the study area. In order for the study area to be geographically evaluated in relation to the solar potential, there are some variables that need to be analyzed, where the main one is the ideal inclination in relation to the receipt of sunlight during the year.

Table 2. Solar potential by aspect.

\begin{tabular}{ccccc}
\hline Aspect/Sun Orientations & Potential & Weight & Area $\left(\mathbf{k m}^{2}\right)$ & Area (\%) \\
\hline Flat & Excellent & 5 & 33.24 & 7.89 \\
North & Very High & 4 & 90.32 & 21.44 \\
Northeast/Northwest & High & 3 & 112.05 & 26.60 \\
West/East & Medium & 2 & 88.30 & 20.96 \\
Southeast/Southwest & Low & 1 & 31.33 & 7.44 \\
South & Null & 0 & 65.98 & 15.66 \\
Total & - & - & 421.23 & 100 \\
\hline
\end{tabular}

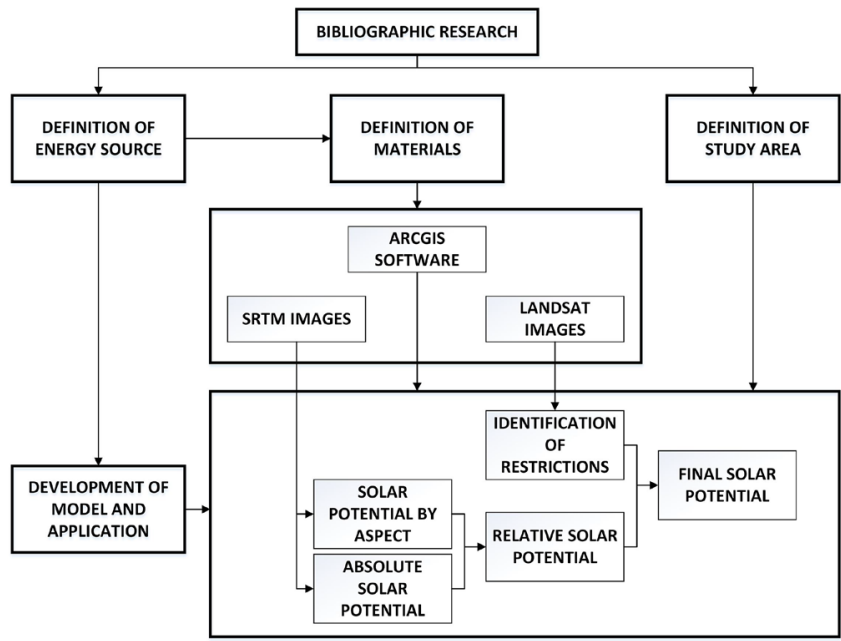

Figure 3. Materials and methods.

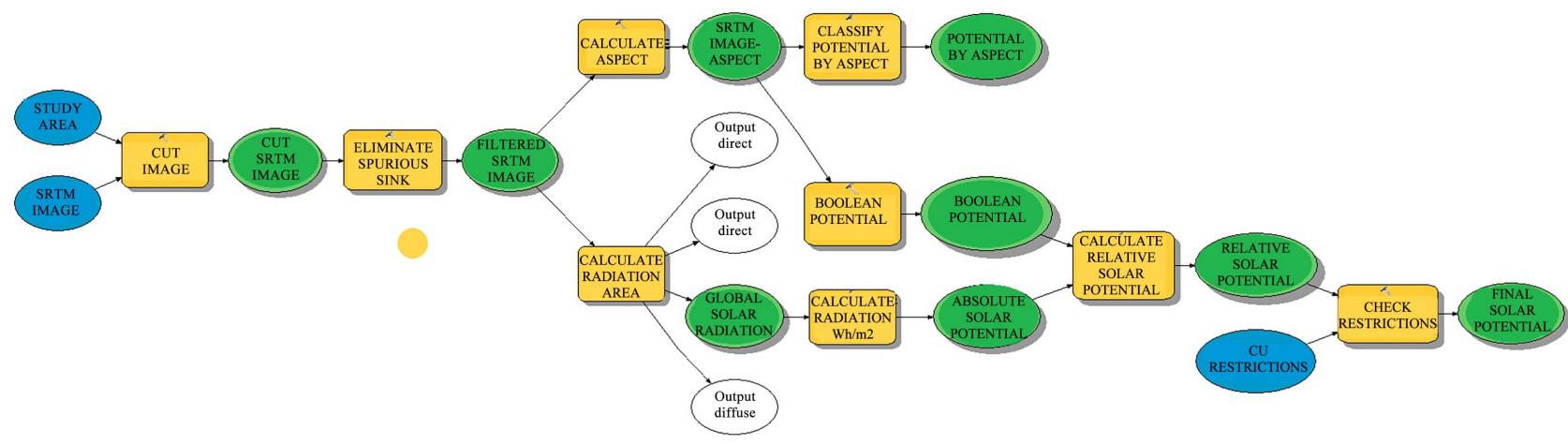

Figure 4. Application of the model. 


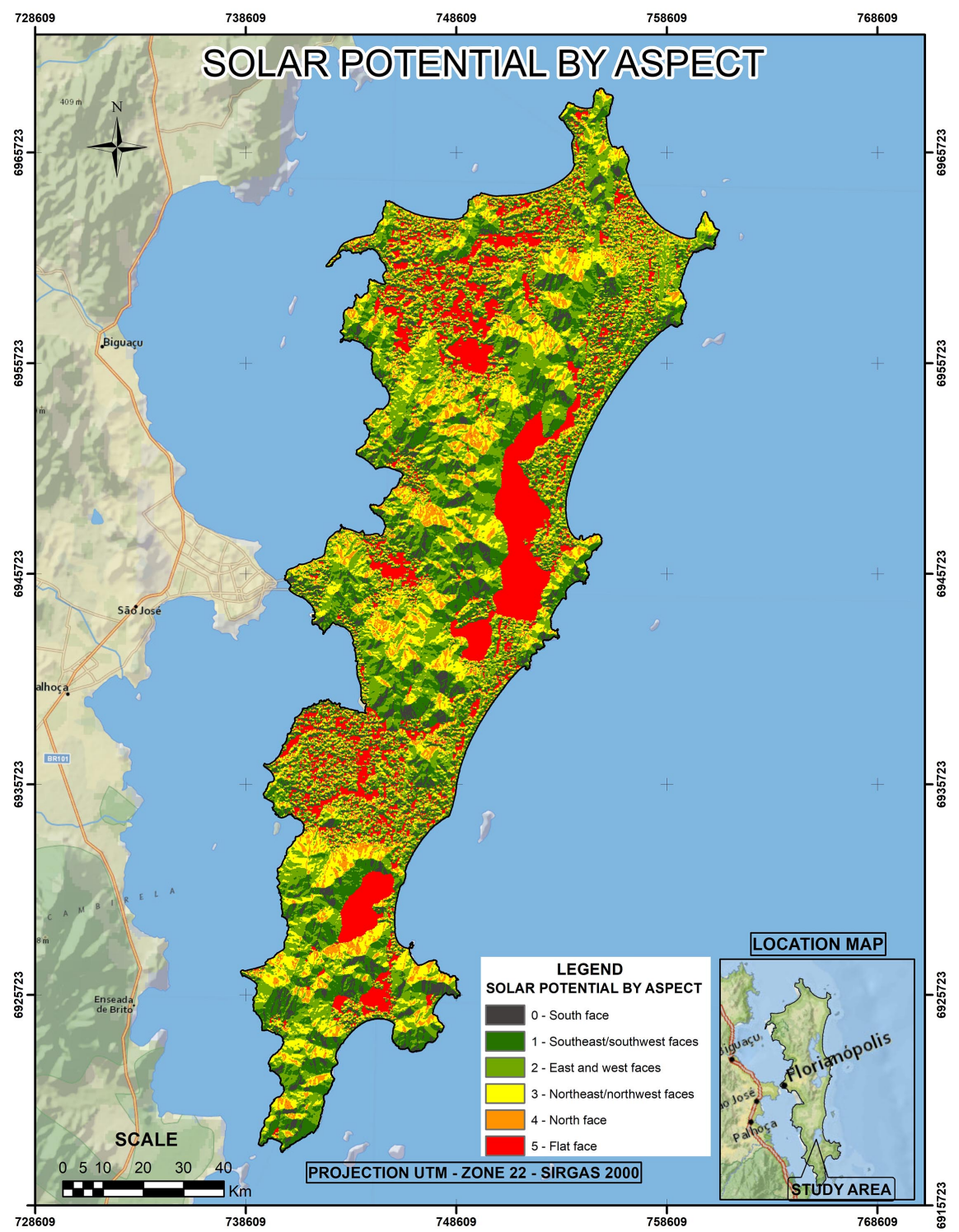

Figure 5. Solar potential by aspect.

Therefore, this study focused on analyzing whether the Florianópolis Island region really had the adequate potential for exploiting solar energy, that is, whether the location's latitude (approximately $27^{\circ}$ South) and whether its orientations of greater insolation incidence, corresponded to the geographic North or the Flat or flat faces. The solar height, which specifies the location of the Sun in space on each day of the year, was not considered. This work used global radiation values for the whole of 2019, regardless of the season or special days.

In this way, it was considered both the best uses of direct solar radiation that occur when the sun's rays strike more and closer to the targets during the summer (more than 14 hours of sun a day), and the worst uses of solar radiation that occur when the rays strike less and more distant from the targets during the winter (only 9 hours of sun per day).

It is noteworthy that the geographical position of Brazil allows the sun to 
strike perpendicularly only to places where the latitude is up to $23^{\circ}$ South, not being the case of the specific study region.

Table 2 and Figure 5 show that approximately $84 \%$ of the investigated region has some solar potential a priori because of its position to the sun, with solar potential by aspect classified between low and excellent. The south face corresponds to $15.66 \%$ of the area and has no solar potential. A priori, the flat face and the northwest, northeast and north faces correspond to the highest potentials assigned, resulting in $55.93 \%$ of the total area, i.e., the area has solar potential by aspect between high and excellent. $28.4 \%$ of the surveyed area also has potential; however, it ranges between low and medium. It is worth mentioning the North, Northeast and Northwest faces, which correspond to $48 \%$ of the total area, because of the geographical location of Florianópolis Island.

After calculating the potential per aspect, the absolute global radiation accumulated for the year 2019 was calculated using the "Area Solar Radiation" tool of ArcGIS. Then, using the Raster Calculator tool, the average daily radiation value was calculated in $\mathrm{wh} / \mathrm{m}^{2}$ for the year 2019 , which resulted in values between 2.188 and $4.564 \mathrm{wh} / \mathrm{m}^{2}$. The map in Figure 6 and the description of the results in Table 3 show that the function for calculating global radiation uses the area as a whole and does not take into account the sun orientations. According to this result, the whole area has solar potential between 2188 and $4.564 \mathrm{wh} / \mathrm{m}^{2}$, which does not correspond to reality.

For a better representation of the solar potential reality, the solar potential per aspect was multiplied to the absolute solar potential, generating the relative solar potential, which is shown in Figure 7 and Table 4, where it can be seen that the areas identified in black have no solar potential because of their position (south face). This corresponds to $7.89 \%$ of the surveyed area.

Figure 7 also shows that there are many areas with solar potential identified in $92.11 \%$ of the area, with radiation calculated between 2.188 and $4.564 \mathrm{wh} / \mathrm{m}^{2}$ (daily average for the year 2019).

In order to identify the solar potential while taking into consideration the restrictions, the Florianópolis Island Conservation Units were subtracted from the relative solar potential map, resulting in the map shown in Figure 8. It can be seen that approximately $17 \%$ of the Island is composed of Conservation Units (shown in blue), and Table 5 shows the values per area of relative solar potential with restrictions.

Figure 8 and Table 5 show that although there is an area of approximately $17 \%$ of CUs on the Island, therefore with no expectation of exploitation of solar potential, there is still $76.73 \%$ of area with relative solar potential to be explored, with radiation values between 2.188 and $4.564 \mathrm{wh} / \mathrm{m}^{2}$ (daily average for the year 2019), and most of the area (63.14\%) has high solar potential with values between 3.903 and $4.564 \mathrm{wh} / \mathrm{m}^{2}$. No other restrictions have been surveyed because it is considered that solar energy can be explored in urban areas and even in lakes/lagoons. 


\section{Conclusions and Final Remarks}

It was concluded that all objectives were achieved because: the information and cartographic products needed to develop the model and the application was defined; a model was implemented in Modelbuilder which resulted in the identification of possible areas with solar potential and; the model in Modelbuilder was applied in a study area for validation. The resulting maps presented satisfactory results, pointing to the solar potential for the study area, that is, Florianópolis Island.

It is considered that: the application of Modelbuilder in different geographic regions depends on a few factors and needs some assumptions to be taken into account, such as the use of DEM for extraction of altitude and aspect (sun orientations), satellite images or rasterized land use and occupation maps to define the possible restrictions.

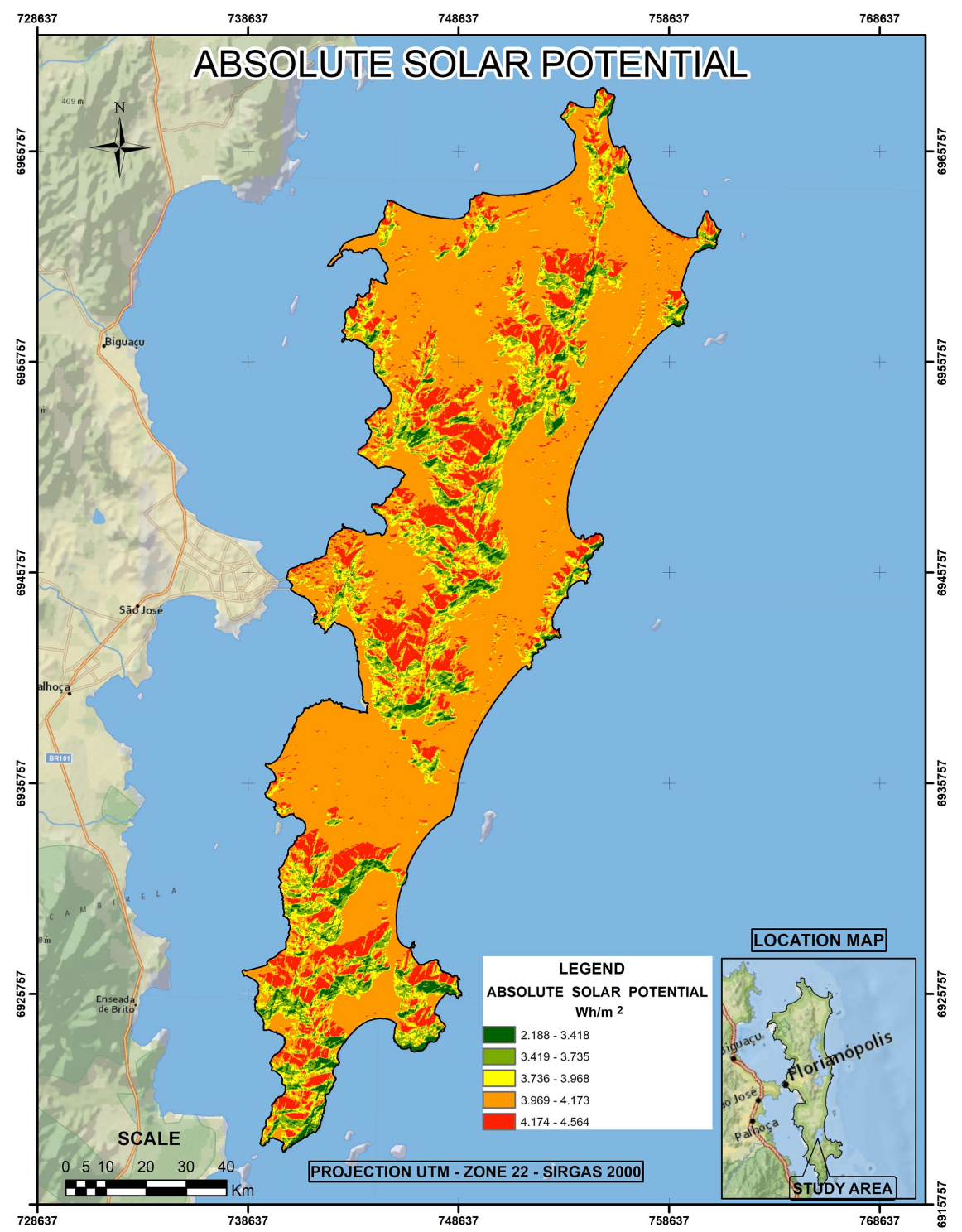

Figure 6. Absolute solar potential-Daily average for the year 2019. 
As to the solar potential of the region, it is concluded that it is high for solar exploration, since more than $76 \%$ of the region has some solar potential, between low and excellent, mainly because of the relief and the geographical situation of the Island, with many north, northeast and the northwest faces.

For the areas with solar potential identified in this work, further studies should be conducted on the type of equipment to be installed (thermal for fluid heating or photovoltaic for power generation), as well as on the use of other models with higher resolutions, such as Digital Surface Models (DSM) from laser surveys or Unmanned Aerial Vehicles (UAVs), to validate and improve results.

It is further recommended that, for applications of this geographical model in other regions of the globe, the following assumptions should be taken into account a priori: existence of DEM and DSM, configuration of parameters for hemisphere, latitude and appearance of the site, as well as verification of the number of hours of sunshine per year, cloudiness and rainfall.

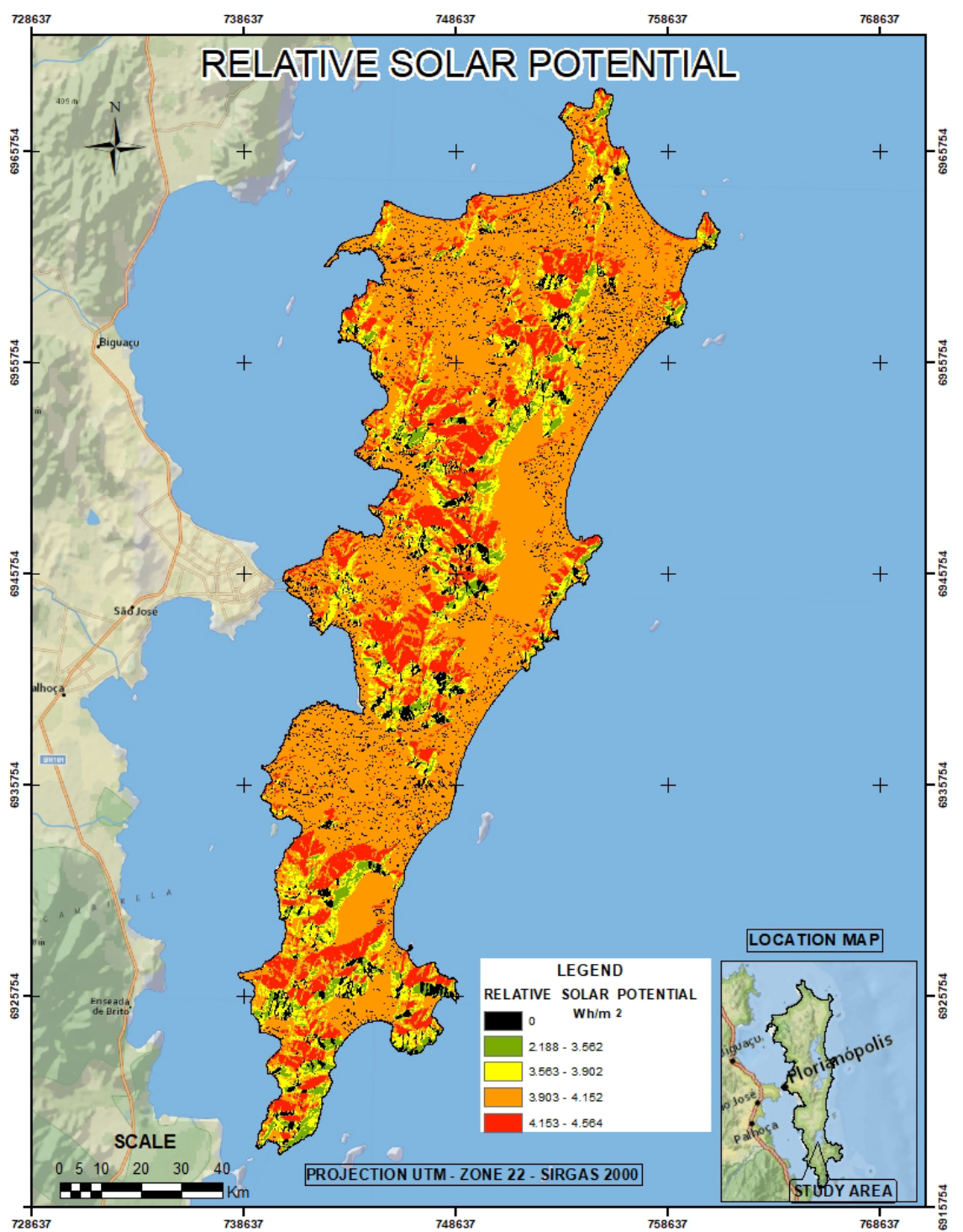

Figure 7. Relative solar potential-Daily average for the year 2019. 
It is concluded that in the study area and also throughout Brazil, there is still a need for studies and discussions involving managers, public and private companies, universities, research centers, among others, to define a long-term strategy

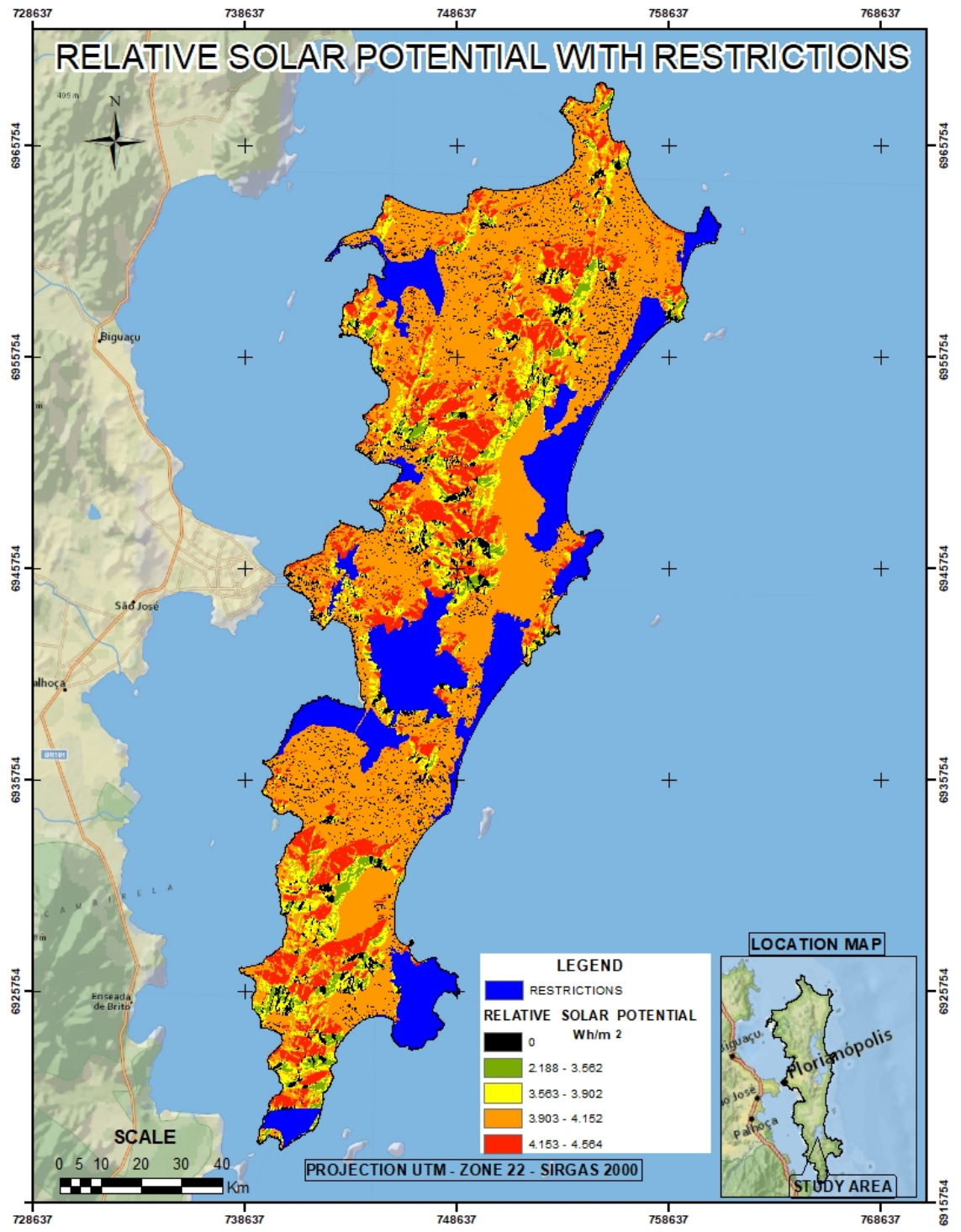

Figure 8. Restricted Relative Solar Potential—daily average for the year 2019.

Table 3. Absolute solar potential-Daily average for the year 2019.

\begin{tabular}{ccc}
\hline Radiation $\left(\mathrm{wh} / \mathrm{m}^{2}\right)$ & Area $\left(\mathrm{km}^{2}\right)$ & Area $(\%)$ \\
\hline Between 2.188 and 3.418 & 12.41 & 2.95 \\
Between 3.419 and 3.735 & 34.79 & 8.26 \\
Between 3.736 and 3.968 & 52.76 & 12.53 \\
Between 3.969 and 4.173 & 267.16 & 63.42 \\
Between 4.174 and 4.564 & 54.11 & 12.85 \\
Total & 421.23 & 100.00 \\
\hline
\end{tabular}


Table 4. Relative solar potential-Daily average for the year 2019.

\begin{tabular}{ccc}
\hline Radiation $\left(\mathrm{wh} / \mathrm{m}^{2}\right)$ & Area $\left(\mathrm{km}^{2}\right)$ & Area (\%) \\
\hline 0 & 33.24 & 7.89 \\
Between 2.188 and 3.562 & 18.17 & 4.31 \\
Between 3.563 and 3.902 & 48.77 & 11.58 \\
Between 3.903 and 4.152 & 258.36 & 61.33 \\
Between 4.153 and 4.564 & 62.69 & 14.88 \\
Total & 421.23 & 100.00 \\
\hline
\end{tabular}

Table 5. Restricted Relative Solar Potential-daily average for 2019.

\begin{tabular}{ccc}
\hline Radiation $\left(\mathrm{wh} / \mathrm{m}^{2}\right)$ & Area $\left(\mathrm{km}^{2}\right)$ & Area (\%) \\
\hline Restriction $(\mathrm{CU})$ & 71.63 & 17.01 \\
Without potential & 26.36 & 6.26 \\
Between 2.188 and 3.562 & 16.37 & 3.89 \\
Between 3.563 and 3.902 & 40.92 & 9.71 \\
Between 3.903 and 4.152 & 212.70 & 50.50 \\
Between 4.153 and 4.564 & 53.25 & 12.64 \\
Total & 421.23 & 100.00 \\
\hline
\end{tabular}

to provide the production of solar energy, with a view to increasing energy demand and availability of high-level solar radiation that can be used throughout the year.

\section{Conflicts of Interest}

The author declares no conflicts of interest regarding the publication of this paper.

\section{References}

[1] Arendt, H. (2000) A condição humana. 10th Edition, Forense Universitária, Rio de Janeiro.

[2] Jensen, J.R. (2011) Sensoriamento Remoto do Ambiente: Uma perspectiva em recursos terrestres. 3th Edition, Parêntese, São José dos Campos.

[3] Hardt, M. and Negri, A. (2004) Multidão: Guerra e democracia na era do império. Record, Rio de Janeiro.

[4] Lovins, A.B. (1977) Soft Energy Paths: Towards a Durable Peace. Penguin Books, Harmondsworth.

[5] Eloy, A. (2009) Energias Sem-fim-Contrariando as Alterações Climáticas. Edições Colibri, Lisboa.

[6] Agencia Nacional de Energia Elétrica ANEEL (2008) Atlas de energia elétrica do Brasil. 3th edição, ANEEL, Brasília, 236 p.

[7] Tiba, C. (2000) Atlas Solarimétrico do Brasil-banco de dados terrestre. Editora Universitária UFPE, Recife, $111 \mathrm{p}$.

[8] Colle, S. and Pereira, E.B. (1998) Atlas de Irradiação Solar do Brasil-1ª versão para 
irradiação global derivada de satélite e validada na superfície. Instituto Nacional de Meteorologia INPE, Brasília, 65 p.

[9] Santos, C.M., Souza, J.L., Teramoto, E.T., Tiba, C. and Melo, R.O. (2014) Modelagem da irradiação solar global média horária mensal $\left(\mathrm{h}_{\mathrm{g}}{ }^{\mathrm{h}}\right)$ para quatro localidades de Alagoas/Brasil. Nativa, Sinop, 2, 79-88. https://doi.org/10.14583/2318-7670.v02n02a04

[10] Fu, P. and Rich, P.M. (1999) Design and Implementation of the Solar Analyst: An ArcView Extension for Modeling Solar Radiation at Landscape Scales. Proceedings of IX Annual ESRI User Conference, San Diego, 26-30 July 1991, 867.

[11] Súri, M., Huld, T.A. and Dunlop, E.D. (2005) PVGIS: A Web-Based Solar Radiation Database for the Calculation of PV Potential in Europe. International Journal of Sustainable Energy, 24, 55-67. https://doi.org/10.1080/14786450512331329556

[12] Mendes, P.G. (2013) Desenvolvimento de uma aplicação SIG no apoio à gestão da rega: O caso de estudo do Alentejo (Portugal). Dissertação (Mestrado em Sistemas de Informação Geográfica) Departamento de Engenharia Geográfica, Geofísica e Energia, Universidade de Lisboa, Lisboa, $147 \mathrm{f}$.

[13] The Solar Analyst 1.0-User Manual. 1999-2000. Helios Environmental Modeling Institute (HEMI).

http://professorpaul.com/publications/fu_rich_2000_solaranalyst.pdf

[14] Hetrick, W.A., Rich, P.M., Barnes, F.J. and Weiss, S.B. (1993) GIS-Based Solar Radiation Flux Models. American Society for Photogrammetry and Remote Sensing Technical Papers, Vol. 3, GIS Photogrammetry and Modeling, 132-143.

[15] Hetrick, W.A., Rich, P.M. and Weiss, S.B. (1993) Modeling Insolation on Complex Surfaces. Thirteen Annual ESRI User Conference, Volume 2, 447-458.

[16] Rich, P.M., Hetrick, W.A. and Saving, S.C. (1995) Modeling Topographic Influences on Solar Radiation: A Manual for the Solarflux Model. Los Alamos National Laboratory Report LA-12989-M. https://doi.org/10.2172/200698

[17] Rich, P.M. (1989) A Manual for Analysis of Hemispherical Canopy Photography. Los Alamos National Laboratory Report, LA-11733-M.

[18] Rich, P.M. (1990) Characterizing Plant Canopies with Hemispherical Photography. Remote Sensing Reviews, 5, 13-29. https://doi.org/10.1080/02757259009532119

[19] Photovoltaic Geographical Information System-PVGIS. https://ec.europa.eu/jrc/en/pvgis

[20] Köeppen, W. (1996) Sistema geográfico dos climas. Trad. Antônio C. de Barros Corrêa. Série B: Textos Didáticos, $n^{\circ} 13$. Departamento de Ciências Geográficas, Recife, UFPE.

[21] Strahler, A.N. (1986) Geografía Física. Ediciones Omega, Barcelona, 767 p.

[22] Monteiro, C.A.F. (1991) Clima e excepcionalismo: Conjecturas sobre o desempenho da atmosfera como fenômeno geográfico. UFSC, Florianópolis.

[23] Debetir, E. and Orth, D.M. (2007) Estratégias de gestão para unidades de conservação. In: Debetir, E. and Orth, D., Eds., Unidades de conservação: Gestão e conflitos, Insular Ltda, Florianópolis, Vol. 1, 43-66.

[24] Pereira, E.B. (2006) Atlas Brasileiro de Energia Solar. Instituto Nacional de Pesquisas Espaciais INPE, Brasília. 